\title{
Battle against COVID-19; Experience of a frontline physician
}

\author{
Millawithana M A B $\mathbf{S}^{1}$ \\ Journal of the Ceylon College of Physicians, 2020, 51, 65-67
}

\section{Early warning}

When the COVID-19 outbreak was first identified in Wuhan, China in early December 2019, it seemed more like a distant trouble that may never reach the shores of Sri Lanka. With the discovery of the first COVID patient, a Chinese tourist, on the $27^{\text {th }}$ of January, we realised that it's only a matter of time before we see a surge of patients.

On the morning of $28^{\text {th }}$ of January, six people were waiting in the isolation area of the Emergency Department (ED) at the Teaching Hospital (TH) Kurunegala, and there was intense panic amongst the staff. Two of them were recent returnees from China and others were workers from the hotels where index case had stayed at. They have come to the hospital requesting a test to exclude COVID-19 as they had travel or contact history. We managed to examine and test them donning the available personal protective equipment (PPE), which were far from ideal to provide adequate protection. Fortunately, none of them had features of COVID-19 infection and we requested them to undergo home quarantine. This was our very first experience.

\section{Getting ready}

Our ED team realized that it was the time to get organized to face the potential impact of COVID-19. These were early days and we had no local guidelines to follow. Meanwhile, TH Kurunegala, the apex tertiary care hospital of the North Western Province with about 2200 bed capacity, was designated as the acute care isolation hospital for the COVID-19 suspected patients for the province by the Ministry of Health $(\mathrm{MoH})$. On $29^{\text {th }}$ January 2020 , a working group was formed to develop a hospital preparedness plan. Multiple areas focused for improvement were, uninterrupted supply of PPEs, development of protocols, improvements in isolation areas, designated intensive care unit and an isolation ward for COVID-19 patients, infection control strategies, staffing and maintenance of staff wellness.

Accordingly, infrastructure improvement of the hospital was a top priority. The existing isolation room of the ED was designated for assessment and resuscitation of COVID-19 suspected patients. This was later upgraded to an intensive care facility. A ward with 8 beds with isolation facilities was allocated to admit suspected patients during the initial period. Preparation of the second isolation ward with 12 single rooms with attached washrooms and refurbishment of another ward as the third ward for COVID suspected admissions increased the total isolation capacity to 40 beds. Consultant Physicians and Respiratory Physicians took over the responsibility of clinical management of patients admitted to the above isolation wards. RT-PCR testing service was organised to an optimal level with the guidance of the $\mathrm{MoH}$ and close collaboration with the virologist of National Hospital, Kandy. Regular PPE supply was established through the $\mathrm{MoH}$, donations and local manufacturing methods.

\section{Guiding the staff}

An internal circular which included a case definition of COVID-19, a checklist for assessment and escalation of COVID-19 suspected patients was issued

\footnotetext{
${ }^{1}$ Resident Physician, Accident and Emergency Treatment Unit, on behalf of the COVID-19 Task Force, Teaching Hospital Kurunegala, Sri Lanka.

Correspondence: E-mail: baranasam@gmail.com
}

iD http://orcid.org/0000-0003-1479-8140

Received 13 May 2020, accepted 22 May 2020.

This is an open-access article distributed under the terms of the Creative Commons Attribution License, which permits unrestricted use, distribution, and reproduction in any medium, provided the original author and source are credited. 
on the $29^{\text {th }}$ January 2020. Our initial case definition was based on the WHO COVID guidelines ${ }^{1}$ and later changed according to the $\mathrm{MoH}$ guidelines which became available on $16^{\text {th }}$ March $2020^{2}$. Based on this circular, medical and nursing officer were assigned to shift work to minimize the exposure while caring for these patients. Decision making with regard to clinical care of COVID suspected at the front desk was manned by the emergency physicians. A series of hospitalbased teaching and training programmes for all health care workers was commenced. We organised workshops for the emergency unit staff on donning and doffing of PPEs and obtaining nasopharyngeal swabs. Training programmes for other hospital staff were also conducted to improve awareness and relieve the fear and anxiety on COVID-19.

And we were ready to face the challenge!

\section{Community engagement}

Envisaging a possible community transmission in future, it was extremely important to establish a link with the community. With this in mind, we had a preliminary meeting with the Consultant Community Physician, Regional Director of Health Services of the Kurunegala district, regional epidemiologist and a few other consultant physicians to create a link between the curative and public health institutions of the province. We took up the responsibility of managing the patients from Medical Officers of Health (MOHs) in the district and the District General and Base hospitals of the province. The Regional Epidemiologist took over the duty of following up of the discharged patients and contacts who were on home quarantine. This invaluable partnership helped us to follow up the patients and contacts in the community. Further, trends, predictions and actions in the community were communicated to us to revise the hospital response accordingly.

\section{Further improvement}

During the period between $28^{\text {th }}$ of January and 10th of March, we managed sixteen hospitalised COVID suspected patients. Even though they were found negative for COVID, this gave us a vital opportunity to identify the deficiencies of the system.

On the $11^{\text {th }}$ of March, with the diagnosis of the first Sri Lankan patient, the hospital went in to an accelerated phase of action. From $12^{\text {th }}$ March, a tidal wave commenced with increasing numbers of COVID19 suspected referrals and direct admissions from the province. In order to continue the uninterrupted services of ED by minimising the nosocomial spread COVID-19, a separate triage, a resuscitation bay and the intensive care isolation room in ED was allocated for patients with respiratory symptoms. To minimise the staff exposure and to save PPEs, physical barriers (glass cabins with two-way communication system) and CCTV facilities were installed. Precautions were taken around aerosolizing procedures. A screening tool was used at the triage to prevent entering of COVID suspects to the non COVID zone. Admission check list for COVID suspects was modified to a user-friendly clerking proforma with disease risk stratification, clinical severity grading and escalation plan. This was to reduce the exposure time of COVID suspects to the staff and reduce the time they spent in the emergency department. A formal task force with a focal point was established in the hospital to strengthen the service delivery and team work.

\section{Influx of patients}

The first positive case of the hospital and Kurunegala district was reported on $14^{\text {th }}$ March, a returnee from Italy with acute respiratory tract infection. Our next positive cases were a mother and a daughter who had returned from Italy, a close contact of a COVID positive case returned from Italy, and a patient who had returned from Indonesia. Last four patients were from the Puttalam district and were detected within a very short time period. This observation of rapid increase of cases and contact information in Puttalam district were passed to the relevant authorities for timely action to prevent community spread. The second case from the Kurunegala district was detected on $1^{\text {st }}$ April, a woman with a close contact to a COVID positive family returning from India. All these positive patients had mild disease with fever and respiratory symptoms (cough and sore throat) and they were transferred to the National Infectious Disease Hospital, Colombo.

Between $2^{\text {nd }}$ to $23^{\text {th }}$ of April, we experienced a reduction in the number of admissions without a single positive case and the routine hospital work gradually resumed. This immense calm was broken by a sudden unexpected surge of patients after a navy solider, a resident of Kurunegala on leave from the Welisara camp, was detected to be positive on $24^{\text {th }}$ April. Over the next seven days, 20 new positive cases were detected with significant contact burden in the community. So far, the hospital has successfully managed about 500 COVID suspected hospitalised patients. 


\section{Sharing experiences}

Local guidelines and proforma were updated in par with the changes in the national guidelines and disseminated among our team. We shared our experiences with them and had regular discussions to listen to their grievances, alleviate fears, to motivate and to look after their wellbeing. Our support and opinion were available to other specialists, such as obstetricians, surgeons, etc whenever needed. We frequently stepped into the community to share our experience with $\mathrm{MOH}$ and empower them with much needed training. We visited the regional hospitals to facilitate staff training and to guide infrastructure development for handling COVID suspects until their transfer is arranged to TH Kurunegala.

The war against COVID needs immense public engagement. Participation in the local radio programs gave us opportunity to educate the public with essential health messages and convey their pivotal role in this mission.

\section{Conclusions}

We have rapidly adopted to a tremendous challenge posed by the COVID pandemic. At present the number of suspected cases are less but we are prepared and experienced to deal with any future catastrophe. Working in the frontline and organising the hospital preparedness for COVID services has been both physically and mentally exhausting. We have a fantastic team at TH Kurunegala, from the administrators to consultant colleagues, dedicated medical officers, nursing staff, attendants and minor staff. The unity and the dedication of the team, early preparedness, leadership and the proactive decision making paved the way for our achievements.

\section{References}

1. World Health Organization. Surveillance case definitions for human infection with novel coronavirus (nCoV): interim guidance v1, January 2020. World Health Organization. https://apps.who.int/iris/handle/10665/330376.

2. Ministry of Health, Sri Lanka, Provisional Clinical Practice Guidelines on COVID-19 suspected and confirmed patients: version4,31 March 2020 http://www.epid.gov.lk/web/ images/pdf/Circulars/Corona_virus/covid-19\%20cpg\% 20_\%20version\%204.pdf 